\title{
Incidence of acute respiratory distress syndrome: a comparison of two definitions
}

\author{
A Y T Goh, P W K Chan, L C S Lum, M Roziah
}

\begin{abstract}
Objectives-To determine the incidence and outcome of acute respiratory distress syndrome (ARDS) in children by comparing two commonly used definitions: the lung injury score and the AmericanEuropean Consensus Conference definition. The causes and risk for developing ARDS were also studied.

Methods-Part prospective and retrospective analysis of 8100 consecutive hospital admissions from 1 June 1995 to 1 April 1997.

Results-Twenty one patients fulfilled the criteria for ARDS. Both definitions identified the same group of patients. The incidence was $2.8 / 1000$ hospital admissions or $4.2 \%$ of paediatric intensive care unit admissions. The main causes were sepsis and pneumonia. Mortality was 13 of 21. Factors predicting death were a high admission paediatric risk of mortality (PRISM) score (30.38 $v$ 18.75) and the presence of multiple organ dysfunction syndrome $(92 \% v 25 \%)$.

Conclusion-Both definitions identified similar groups of patients. The incidence in this population was higher than that reported elsewhere, but mortality and cause were similar to those in developed countries. Poor outcome was associated with sepsis, a high admission PRISM score, and simultaneous occurrence of other organ dysfunction.

(Arch Dis Child 1998;79:256-259)
\end{abstract}

Keywords: acute respiratory distress syndrome; lung injury score; American-European Consensus Conference

Ashbaugh and colleagues ${ }^{12}$ first described a group of patients with a characteristic pattern of respiratory distress, with hypoxaemia refractory to supplementary oxygen, decreased lung compliance, and diffuse alveolar infiltrates. This was secondary to widespread alveolar capillary damage from various pulmonary and systemic disorders, leading to permeability pulmonary oedema. The identified risk factors were sepsis, aspiration of gastric contents, trauma, pneumonia, fractures, and disseminated intravascular coagulopathy. According to a large population study in New York, the reported incidence in adults is about 150000 cases/year. ${ }^{3}$ The incidence in children has not been well studied ${ }^{3}$ with a mortality of $59 \%$ from five retrospective studies. ${ }^{4-8}$ All of these studies were conducted in developed countries, which have different patient and population characteristics from a developing country like Malaysia.

Part of the difficulty in determining the incidence of acute respiratory distress syndrome (ARDS) results from the heterogeneity of definitions used. In children, this is compounded by unavailability and the age and size dependent variability in measurements of pulmonary capillary wedge pressure, which formed the cornerstone of earlier definitions of ARDS. Murray and colleagues ${ }^{9}$ offered a useful and practical definition of ARDS that did not rely on pulmonary capillary wedge pressure measurements, using the lung injury score. A lung injury score of $>2.5$ indicates ARDS. The American-European Consensus Conference (A-ECC) definition for ARDS was introduced in 1994 in an effort to streamline current definitions of ARDS, with the exclusion of positive end expiratory pressure (PEEP) values and compliance measurements to improve detection of early and true cases. ${ }^{10}$ We set out to determine the incidence and outcome of ARDS in Malaysia in children together with identification of its aetiology, and in the process compare the accuracy of both definitions.

\section{Materials and methods}

We carried out a part prospective and retrospective analysis of 8100 consecutive admissions to our paediatric department from 1 June 1995 to 1 April 1997, the last six months being prospective. Cases of respiratory failure were routinely admitted to the paediatric intensive care unit (PICU) and detailed analysis was carried out on these patients. The University Malaya Medical Centre is located in Kuala Lumpur, the capital of Malaysia. It serves a local population of 2.1 million and forms a tertiary referral centre for the nation. The paediatric department has 116 non-intensive care beds and a six bedded multidisciplinary PICU, which is staffed by one intensivist and has 24 hour physician coverage.

The lung injury score was determined by two to four criteria, each individually based on a four point scale (table 1). The score was derived by dividing the aggregate sum by the number of components used. The worst daily values were used to calculate the $\mathrm{PaO}_{2} / \mathrm{FiO}_{2}$ ratio and PEEP score in determining the overall lung injury score. In addition, the absence of a clinically apparent cardiogenic cause for the pulmonary oedema was added as a criterion. The radiographs were reported and scored by a radiologist for the appearance of bilateral diffuse alveolar infiltrates and absence of cardiomegaly. Patients were defined as having ARDS if any of the daily lung injury scores were $>2.5$ 
Table 1 Lung injury score

\begin{tabular}{|c|c|}
\hline & Value \\
\hline \multicolumn{2}{|l|}{ Chest $x$ ray score } \\
\hline No alveolar consolidation & 0 \\
\hline Alveolar consolidation in one quadrant & 1 \\
\hline Alveolar consolidation in two quadrants & 2 \\
\hline Alveolar consolidation in three quadrants & 3 \\
\hline Alveolar consolidation in four quadrants & 4 \\
\hline \multicolumn{2}{|l|}{ Hypoxaemia score } \\
\hline $\mathrm{PaO}_{2} / \mathrm{FiO}_{2}>300$ & 0 \\
\hline $\mathrm{PaO}_{2} / \mathrm{FiO}_{2} 225-299$ & 1 \\
\hline $\mathrm{PaO}_{2} / \mathrm{FiO}_{2} 175-224$ & 2 \\
\hline $\mathrm{PaO}_{2} / \mathrm{FiO}_{2} 100-174$ & 3 \\
\hline $\mathrm{PaO}_{2} / \mathrm{FiO}_{2}<100$ & 4 \\
\hline \multicolumn{2}{|c|}{$\begin{array}{l}\text { Positive end expiratory pressure score (when ventilated) } \\
\left(\mathrm{cm} \mathrm{H}_{2} \mathrm{O}\right)\end{array}$} \\
\hline$<5$ & 0 \\
\hline $6-8$ & 1 \\
\hline $9-11$ & 2 \\
\hline $12-14$ & 3 \\
\hline$>15$ & 4 \\
\hline \multicolumn{2}{|c|}{$\begin{array}{l}\text { Respiratory system compliance score (when ventilated) } \\
\left(\left(\mathrm{ml} / \mathrm{cm} \mathrm{H}_{2} \mathrm{O}\right)\right.\end{array}$} \\
\hline$>80$ & 0 \\
\hline $60-79$ & 1 \\
\hline $40-59$ & 2 \\
\hline 20-39 & 3 \\
\hline$<19$ & 4 \\
\hline \multicolumn{2}{|l|}{ Final score ${ }^{\star}$} \\
\hline No lung injury & 0 \\
\hline Acute lung injury & $0.1-2.5$ \\
\hline Severe injury (ARDS) & $>2.5$ \\
\hline
\end{tabular}

*Obtained by dividing the aggregate sum by the number of components that were used.

and there was no clinical evidence of cardiogenic pulmonary oedema. In addition, we applied the A-ECC definitions for ARDS (table 2) to determine their accuracy and to compare whether the two scores identified a similar population of patients. The A-ECC definitions excluded measurements of PEEP and the four point radiographic scoring system, and used the presence of bilateral alveolar infiltrates consistent with pulmonary oedema as criteria instead. The aetiology of ARDS was also studied in these patients together with their epidemiological data. The admission PRISM score was calculated and the presence of multiple organ dysfunction syndrome was noted using Wilkinson's criteria. ${ }^{11}$ Factors associated with mortality were determined and compared using the $\chi^{2}$ test.

All 21 case notes were reabstracted after completion of the scoring and scored again. An

Table 2 The American-European Consensus Conference definition of ARDS (1994)

\begin{tabular}{ll}
\hline Oxygenation & $\mathrm{PaO}_{2} / \mathrm{FiO}_{2}<200$ (regardless of positive end \\
expiratory pressure level)
\end{tabular}

Table 3 Characteristics of non-survivors compared with survivors

\begin{tabular}{llll}
\hline Clinical parameters & Survivor & Non-survivor & p value \\
\hline Age (months) & 18.0 & 63.3 & 0.02 \\
$\mathrm{Sex}(\mathrm{M}: \mathrm{F})$ & $1: 1$ & $1.4: 1$ & 0.47 \\
Admission PRISM & 18.75 & 30.38 & 0.001 \\
$\mathrm{MODS}$ & $25 \%$ & $92 \%$ & 0.003 \\
Lung injury score* & 3.32 & 3.49 & 0.18 \\
$\mathrm{PEEP}^{\star}\left(\mathrm{cm} \mathrm{H}_{2} \mathrm{O}\right)^{\star}$ & 8.13 & 12.23 & 0.06 \\
$\mathrm{PaO}_{2} / \mathrm{FiO}_{2}$ & 72.4 & 95.9 & 0.04 \\
$\mathrm{Sepsis}^{\text {Barotrauma }}$ & $1 / 8(12.5 \%)$ & $8 / 13(61.5 \%)$ & 0.07 \\
& $1 / 8(12.5 \%)$ & $1 / 13(7.7 \%)$ & 0.07 \\
\hline
\end{tabular}

${ }^{\star}$ Mean values.

MODS, multiple organ dysfunction syndrome. abstraction/reabstraction ratio of $>0.8$ $(\kappa=0.88)$ was indicative of almost perfect interrater reliability. Proportions were compared where appropriate with the Fischer's exact test and quantitative data were compared with the Student's $t$ test. p values $<0.05$ were considered significant.

\section{Results}

Of the 494 patients admitted to the PICU, 21 fulfilled criteria for ARDS based on the lung injury score and A-ECC definitions for ARDS. The incidence of ARDS in our hospital during this study period was $2.8 / 1000$ hospital admissions or $4.2 \%$ of all PICU admissions. Patients with ARDS had a median age of 28 months (range, 2-144), with more than two thirds being less than 5 years old. The boy to girl ratio was 1.4:1. Almost all patients fulfilled the criteria within 24 hours of admission to the PICU (20 of 21). One patient with pneumococcal sepsis developed ARDS after three days of ventilation.

The median lung injury score was 3.6 with a mean (SD) of 3.36 (0.52). The median PRISM score was 28 with a mean (SD) of 25.9 (8.7). Multiple organ dysfunction syndrome was present in more than half of the patients. Sepsis was the main cause of ARDS (nine patients), followed by pneumonia (seven patients), dengue shock syndrome (two patients), aspiration of kerosene, meningitis, and drug induced (one patient each). The main bacteriological isolates (blood cultures) from the sepsis group were Gram negative in five patients and Gram positive in three others. Nine of the patients had an underlying illness, five had acute leukaemia and two had chromosomal disorders.

Death from ARDS was three times higher (13 of 21) than the overall PICU mortality of $17.2 \%$ ( $\mathrm{p}<0.005)$. Analysing subsets of patients, mortality was highest in the sepsis group and lower in pneumonia. Non-survivors had a higher mean PRISM score (30.38 v 18.75; $\mathrm{p}=0.001)$ and a higher incidence of multiple organ dysfunction syndrome $(92 \% \quad v \quad 25 \%$; $\mathrm{p}=0.003)$. There was no difference in the mean PEEP (8.1 $v$ 12.2), mean duration of PICU stay (11.2 v 5.3 days), mean lung injury score (3.32 $v 3.49)$, and incidence of barotrauma between survivors and non-survivors, respectively. Survivors had a lower worst $\mathrm{PaO}_{2} /$ $\mathrm{FiO}_{2}$ than non-survivors (72.4 v 95.9; $\mathrm{p}=0.04)($ table 3$)$.

\section{Discussion}

Since the classic description of ARDS by Ashbaugh 30 years ago, ${ }^{12}$ the study of ARDS and its risk factors has been hampered by the heterogeneity and lack of uniformity in definitions. Murray and colleagues proposed an expanded definition, in an effort to improve sensitivity and specificity, by including early and true cases of ARDS. ${ }^{9}$ This score has been used in several clinical studies. ${ }^{12-15}$ Studies in children have an additional compounding factor in that the previously accepted term for ARDS was the adult respiratory distress syndrome, implying that it occurred mainly in 
adults, thus limiting research in this field of critically ill children with hypoxaemic respiratory failure. The A-ECC proposed that "acute" better encompassed the spectrum of clinical and radiological abnormalities seen in this syndrome and that ARDS was not limited to adults.

The consensus conference definitions differed from the lung injury score in four areas: (1) The A-ECC definitions did not use a four point chest $x$ ray scoring system and instead looked for the appearance of bilateral infiltrates; (2) PEEP measurements were excluded in an effort to reduce variability in utilisation of PEEP by individual physicians; (3) a different degree of hypoxaemia was required for the oxygenation criteria; and (4) they included either measurements of pulmonary artery occlusion pressure or absence of clinical evidence of left atrial hypertension. In our study, both scores identified the same group of patients despite differing criteria used in the definitions. The addition of PEEP requirement as a criterion in the lung injury score did not alter the sensitivity and specificity of the score, as shown previously by Moss. ${ }^{16}$ The use of PEEP in restoring functional residual capacity in patients with acute lung injury (ALI)/ARDS in our unit is well accepted. Almost all our patients had a four point score from the chest $x$ ray value in the lung injury score, which would approximate with the chest radiograph finding of diffuse bilateral infiltrates in the A-ECC definition. All patients had a $\mathrm{PaO}_{2} / \mathrm{FiO}_{2}$ of $<175$, thus fulfilling both definitions of ARDS. Considerable discussion has been centred around the cut off between ALI and ARDS with regard to the $\mathrm{PaO}_{2} / \mathrm{FiO}_{2}$, with many suggesting a cut off value of $<150$ rather than $<200$. Concerns were that the more liberal definitions might include non-ARDS related illnesses with altered gas exchange. Our data support a cut off value of $<200$ for detecting true cases of ARDS when compared to the lung injury score, which has a more stringent cut off point for hypoxaemia. We did not measure pulmonary artery occlusion pressure, which has been shown not to improve substantially the ability to diagnose ARDS. ${ }^{16}$

The incidence of ARDS in our hospital population is higher than quoted elsewhere but mortality appears to be similar. ${ }^{17}{ }^{18}$ This could be explained by the fact that University Hospital, Kuala Lumpur is a national referral centre for childhood oncology patients, who accounted for a significant proportion of the study group and a high percentage of those who died. In addition, patients in developing countries might present late as a result of socioeconomic and cultural factors, at the height of their illness, and with maximal organ failure. This was supported by the fact that criteria for ARDS and multiple organ dysfunction syndrome were met in almost all our paediatric patients with ARDS within 24 hours of admission to the PICU. Chronic shortage of PICU beds was a further compounding factor, with critically ill patients being cared for in nonintensive care areas, until further deterioration requiring ventilator support caused them to be transferred to the PICU.

The causes and risk factors for developing ARDS in our population were similar to those in developed countries. ${ }^{45-20}$ Sepsis remains the commonest cause of ARDS, often in immunocompromised children on long term chemotherapy. Severe pneumonia was the second commonest cause and had a better outcome, especially if there was no accompanying multiple organ dysfunction syndrome. Dengue virus infection is a known cause of ARDS in the tropics, especially cases of dengue shock syndrome. ${ }^{21}$ The pathophysiology of severe dengue infection is that of increased capillary permeability, which partially explains the changes in the respiratory system. Other recognised causes were central nervous system infections, drug ingestion, and aspiration pneumonia.

Sepsis, particularly Gram negative, was associated with a poor outcome. Severe Gram negative infection in chronically immunocompromised, debilitated children with malignancies and accompanying neutropenia was often fatal, once the stage of severe respiratory failure and organ dysfunction was reached. Only one patient with leukaemia, ARDS, and respiratory failure survived-a non-neutropenic child with Pneumocystis carinii pneumonitis without multiorgan dysfunction. Other authors have quoted survival rates of only $10 \%$ in this group of patients. ${ }^{22}$ ARDS in Gram positive sepsis had a slightly better prognosis because it was less likely to be associated with hypotension and multiple organ failure.

Multiple organ dysfunction syndrome is a primary life threatening situation in ARDS, arising from the same generalised activation of inflammatory cells responsible for the systemic inflammatory response seen in ARDS. Over half of our patients had multiple organ dysfunction syndrome, many of whom died. The commonest dysfunctional organ (other than the respiratory system) was haematological, with disseminated intravascular coagulopathy. As in most series of patients with multiple organ dysfunction syndrome, ${ }^{11}{ }^{23-25}$ our paediatric patients with ARDS typically presented early, with maximal organ dysfunction at presentation or within 24 hours of PICU admission. This pattern differed from adult patients, who present with sequential organ failure, suggesting that there may be differing age related responses to similar insults.

A high admission PRISM score was also significantly associated with death. This score has been validated recently in Malaysia (Goh AYT, unpublished data, 1997) and shown to predict death across different diagnostic groups, as well as mortality risk intervals. The use of severity of illness scores using non-pulmonary factors has been used widely. ${ }^{26-29}$ Prognostic scores in ARDS should use routinely measured variables in these patients. Serial measurements of oxygenation index $\left(\mathrm{PaO}_{2} / \mathrm{FiO}_{2}\right)$ and the total lung injury score were unreliable prognostic factors in our study. Surprisingly, nonsurvivors had a better $\mathrm{PaO}_{2} / \mathrm{FiO}_{2}$ than survivors. The outcome appears to be linked more 
to the cause of ARDS and associated organ dysfunction rather than the severity of the oxygenation deficit itself.

There were several problems associated with our study. It relied partly on retrospective data collection, which would weaken the incidence estimates because of the possibility of undiagnosed cases. We believe that this was minimised because all cases of respiratory failure/ALI/ ARDS were managed in the PICU. The reliance on clinical assessment for absence of left atrial hypertension together with radiological interpretation of diffuse bilateral alveolar infiltrates could introduce bias. However, previous studies have shown the accuracy of these scores in diagnosing ARDS compared with a more rigid definition, which included static respiratory system compliance and pulmonary artery occlusion pressure measurements. ${ }^{16}$ The possibility of overestimating the lung injury score was limited by aiming for an abstraction/reabstraction ratio of $>0.8$.

The current understanding of ARDS is that it is the severe end of a continuum of diseases affecting the respiratory system from both pulmonary and non-pulmonary insults, resulting in the characteristic clinical spectrum of arterial blood gas and chest radiographic abnormalities. Improved and accurate definitions would lead to better knowledge of its true incidence and outcome. This in turn would lead to better recognition of risk factors for ARDS, allowing preventive strategies and early treatment to improve outcome in these critically ill children.

1 Ashbaugh DG, Bigelow DB, Petty TL, et al. Acute respiratory distress in adults. Lancet 1967;ii:319-21.

2 Ashbaugh DG, Petty TL, Bigelow DB, et al. Continuous positive pressure breathing (CPPB) in adult respiratory distress syndrome. 7 Thorac Cardiovasc Surg 1969;57:3141.

3 National Heart and Lung Institute (DHEW). Respiratory diseases. Task force report on problems, research approaches, diseases. Task force report on problems, research approaches, needs. NIH Publication No. 73-432. Washingt 4 Holbrook PR, Taylor G, Pollack MM, Fields HJ. Adult res-
piratory distress syndrome in children. Pediatr Clin North piratory distress syndrome in children. Pediatr Clin North Am 1980;27:677-85.

5 Pfenninger J, Gerber A, Tschappeler H, Zimmermann A. Adult respiratory distress syndrome in children. $\mathcal{F}$ Pediat 1982;101:352-7.

6 Nussbaum E. Adult-type respiratory distress syndrome in children: experience in seven cases. Clin Pediatr 1983;22 401-6.
7 Effmann EL, Merten DF, Kirk DR, et al. Adult respiratory distress syndrome in children. Radiology 1985;157:69-74 8 Truog WE. ARDS in children: a critical care challenge. $f$ Respir Dis 1986;7:104-119.

9 Murray JF, Matthay MA, Luce JM, et al. An expanded definition of the adult respiratory distress syndrome. Am Rev Respir Dis 1988;138:720-3.

10 Bernard GR, Artigas A, Brigham KL, et al. Report of the American-European consensus conference on ARDS: definitions, mechanisms, relevant outcomes, and clinical trial co-ordination. Am $\mathcal{F}$ Respir Crit Care Med 1994;149:81824.

11 Wilkinson JD, Pollack MM, Ruttimann UE, et al. Outcome of paediatric patients with multiple organ system failure. Crit Care Med 1986;14:271-8.

12 Meduri GU, Belenchia JM, Estes RJ, et al. Fibroproliferative phase of ARDS: clinical findings and effect of corticosteroids. Chest 1991;100:943-52.

13 Kraus PA, Lipman J, Lee CCJ, et al. Acute lung injury at Baragwanath ICU: an eight-month audit and call for consensus for other organ failure in the adult respiratory distress syndrome. Chest 1993;103:1832-6.

14 Lewandowski K, Metz J, Preib H, et al. Incidence, severity and mortality of acute respiratory failure in Berlin/ Germany: a prospective multicenter trial in 72 intensive care units [abstract]. Am Rev Respir Dis 1993;147:A349.

15 Suter PM, Domenighetti G, Schaller M, et al. $\mathrm{N}$-acetylcysteine enhances recovery from acute lung injury in man. Chest 1994;105:190-4.

16 Moss M, Goodman PL, Heinig M, et al. Establishing the relative accuracy of three new definitions of the adult respiratory distress syndrome. Crit Care Med 1995;23:1629-37.

17 Lyrene RK, Truog WE. Adult respiratory distress syndrome in a paediatric intensive care unit: predisposing conditions, clinical course, and outcome. Pediatrics 1981;67:790-9.

18 Costil J, Cloup M, Leclerc F, et al. Acute respiratory distress syndrome (ARDS) in children: multicenter collaborative study of the French group of pediatric intensive care. Pediatr Pulmonol Suppl 1995;11:106-7.

19 Garber BG, Herbert PC, Yelle JD, Hodder RV, McGowan J. Adult respiratory distress syndrome: a systemic overview of incidence and risk factors. Crit Care Med 1996;24:687-95.

20 Hudson LD, Milberg JA, Anardi D, Maunder RJ. Clinical risks for development of the acute respiratory distress syndrome. Am F Respir Crit Care Med 1995;151:293-301.

21 Lucy LCS, Thong MK, Cheah YK, Lam SK. Dengueassociated adult respiratory distress syndrome. Ann Trop Paed 1995;15:335-9.

22 Randle CJ Jr , Frankel LR, Amylon MD. Identifying early predictors of mortality in paediatric patients with acute leukaemia and pneumonia. Chest 1996;109:457-61.

23 Proulx F, Fayon M, Farrel CA, Lacroix J, Gauthier M. Epidemiology of sepsis and multiple organ dysfunction in children. Chest 1996;109:1033-7.

24 Proulx F, Gauthier M, Nadeau D, et al. Timing and predictors of death in pediatric patients with multiple organ system failure. Crit Care Med 1994;22:1025-31.

25 Krafte Jacobs B, Pollack MM. Multiple organ system failure in children. Crit Care Med 1994;22:903-4.

26 Pollack MM, Ruttimann UE, Getson PR. Pediatric risk of mortality (PRISM) score. Crit Care Med 1988;16:1110-16.

27 Pollack MM, Kantilal M, Ruttimann UE. PRISM III: an updated pediatric risk of mortality score. Crit Care Med 1996;24:743-52.

28 Shann F, Pearson G, Slater A, Wilkinson K. Paediatric index of mortality (PIM): a mortality prediction model for children in intensive care. Intensive Care Med 1997;23:201-7.

29 Pearson G, Shann F, Barry P, et al. Should paediatric intensive care be centralised? Trent versus Victoria. Lancet 1997;349:1213-17. 